\title{
Association of Microbodies with Induced Resistance to Tobacco Mosaic Virus in \\ Hypersensitive Tobacco
}

\section{By}

MARVIN EDWARD MILLER

A DISSERTATION PRESENTED TO THE GRADUATE COUNCIL OF THE UNTVERSTTY OF FLORIDA IN PARTIAL FULFILLMENT OF THE REQUIREMENTS FOR THE DEGREE OF. DOCTOR OF PHILOSOPHY

UNIVERSITY OF FLORIDA

1971 
I wish to thank Dr. D. A. Roberts, Chairman of the Supervisory Committee, for his guidance and advice throughout this study; and for his critical assistance in tho preparation of this manuscript. I also wish to thank the other members of my Committee, Drs. J. W. Kimbrough, R. C. Smith, and F. W. Zettlor for their critical reviow or this manuscript.

Acknowledgments are also extended to Miss Betty Cordon for hor technical assistance and to Mr. Richard Christie for his generous advice on siaining techniques. Thanks are also due Dr. J. R. Edwardson for the use or his equipment. 
Page

ACKNOWLEDGNENTS. . . . . . . . . . . $1 i$

LIST OF FIGURES. . . . . . . . . . . iv ABSTRACT ................ . . v INTRODUCTION ...................... 1 NETHODS OF INOCULATTON . . . . . . . 3 - IDENTITY OF MICROBODIES IN HEALTIY AND VIRUS-INFECTED TOBACCO............. 5 Staining and Counting Microbodies.... 5 Catalase Activity in Microbodies of Epiciermal cells........... 9

THE INCREASE IN NURBER OF MTCROBODIES IN RELATION TO SYSTENIC INDUCED RESTSTANCE OF TOBACCO TO TMV. ....................... 13 DISCUSSTON . . . . . . . . . 22 SUMMARY. . . . . . . . . . . . 26 LITERATURE GTTED . . . . . . . . 28 BIOGRAPHICAL SKETCH. . . . . . . . . 30 


\section{LIST OF FIGURES}

Figure

Page

1. Crysta11oid inciusions of microbodies (M) in

epidermal celis that had not been treated

vith Triton X-100 to remove chloroplasts... . 6

2. Crystalloid inclusions of microbodies (N) in

epidermal cells treated with Triton X-100 to

remove chloroplasts..'. . . . . . . 8

3. Crystalloid inclusions of microbodies (M)

treated with diaminobenzidine and $\mathrm{OSO}_{4}$ for

Localization of catalase activity . . . . . 11

4. Average number of microbodies in 40 cells

fron two epidermal strips of leaves of

control plants which were not inoculated. . . 14

5. Average number of microbodies in 60 cells

from three epidemal strips of leaves of

control plants which were only inoculated

on the throe lover leaves with TIV $\left(10^{-4}\right) \cdot$. 15

6. Average number of microbodies in 140 celis

from seven epidermal strips of leaves of

plants which vere inoculated on the three

lower leaves with TMV $\left(10^{-4}\right)$ and sevon days

later ingculated on tho two upper leaves with

TMV $\left(10^{-5}\right)$. . . . . . . . . . 17

7. Average number of microbodies in 80 cells

from four epidermal strips from leaves of

plants which were only inosilated on the

upper two leaves with TMV $\left(10^{-5}\right) . . . . . .18$ 
Abstract of Dissertation Presented to the Graduate Council of the University of Florida in Partial Fulfillment of the Requirements for the Degree of Doctor of Philosophy

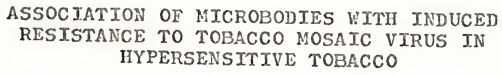

By

Marvin Edward Miller

$$
\text { June, } 1971
$$

Chairman: Dr. D. A. Roberts

Major Department: Plant Pathology

Numbers of microbodies in lower epidermal cells of upper leaves of hypersensitive tobacco increased just before reduction in the rate of enlargement of lesions induced by tobacco mosaic virus. In control plants, inoculated only on two upper leaves of decapitated plants, there was a 1.6-fold increase in the number of microbodies four days following inoculations. In challenge plants, inoculated first on three lower leaves, and seven days later inoculated on the two upper leaves, there was a 1.5-fold increase in microbody-count in upper leaves only one day following the second inoculation; numbers of microbodies almost doubled within 48 hours of the second inoculation. In control leaves, the diameters of the lesions increased more than $0.2 \mathrm{~mm}$ per day for four days following the appearance of the lesions; but lesions in challenged leaves increased less than $0.2 \mathrm{~mm}$ per day following the 
day the lesions appeared. In both control and challenge leaves, the number of microbodies increased prior to the reduction in lesion growth, but both the increase of microbodies and the reduction of lesion growth occurred three days earlier in challenge leaves than in control 1eaves. For this reason it is thought that microbodies may be associated with the development of induced resistance in challenge leaves, and that induced resistance is but an acceleration of the normal plant processes that restrict lesion size in a hypersensitive host. 


\section{INTRODUCTION}

Infection in one part of a hypersensitive host plant induces localized and systemic resistance in noninoculated parts of that plant. This resistance is characterized by the fallure of localized lesions induced by subsequent viral inoculations to develop to normal size $(1,13,14,15)$. This fallure is thought to result from enhancement of the plant-defense reactions that normally restrict lesion size in a hypersensitive host (15).

Numerous attempts have been made to determine differences between plants that exhibit induced resistance and those that do not. Simons and Ross $(17,18)$ reported increased peroxidase and catalase activities prior to lesion forma tion in the systemically resistani upper leaves of plants whose lower leaves had been previous $1 y$ inoculated with a local-1esion strain of a virus. They suggested that the increased peroxidase activity might play a role in the development of systemic acquired resistance (17).

Israel and Ross (8) reported finding single membranebounded organelles, which contained crystalloid inclusions, in a zone of cells of the palisade parenchyma surrounding the lesions in leaves exhibiting systemic acquired resistance. These organelles were not found in parenchymatous ce11s 
surrounding lesions in. leaves that did not exhibit systemic acquired resistance. They suggesied the possibility that these organelles might play some role in the mechanism of resistance. Zimmer (21) also found similar organelles, which he referred to as crystal-containing microbodies, in cells in the region where exclusionary-seedling-rust resistance was operativo in safflower. He suggested that the crystal-containing microbodies might play an important role in the rust-resistance mechanism in safflower.

The organelles referred to by Israel and Ross (8) and by $\mathrm{zimmer}(21)$ are apparently the same as those reported by Frederick et al., who first referred to them as cytosomes (6), and later as microbodies $(5,7)$. Nollenhaver et al. (11) reported that cytosomes, which fit the description of the microbodies described by Frederick and Newcomb $(5,7)$, are widespread throughout the plant kingdom and are located in many different organs of healthy plants.

Because of the reports that cellular organe11es, which resemble the microbodies described by Frederick et al. (5) and Frecerick and Newcomb (7) might be involved in plant defense reactions, a study was undertaken to determine if numbers of microbodies were affected by the acquisition of systemic resistance to tobacco mosaic virus (TMV) in hypersensitive tobacco. 


\section{METHODS OF INOCULATION}

The test plant usod in all experinents was Nicotiana tabacum L. 'Samsun NN', which is hypersensitive to infection by TMV. Plants were grown in composted soil in four-inch pots kept in a greenhouse until ready for inoculation. Vigorousiy growing plants with five or six well expanded leaves were decapitated and trimmed to five adjacent leaves as described by Ross (14). The lower three leaves were dusted with 600-mesh Carborundum and inoculated by the gauze-pad method with TNV in the juice of systemically infected Turkish tobacco (N. tabacum); crude juice was diluted to $10^{-4}$ in $0.1 \mathrm{M}$ neutral potassium phosphate burfer. Seven days later, the two upper leaves were similarly inoculated with TMV in juice diluted to $10^{-5}$ in the same buffer. This inoculum caused approximately 100-150 discreto lesions to form on each of the upper leaves.

Similar control plants were decapitated and trimmed as the treated plants, and received the following treatments: 1) the three lower 1 eaves were rubbed with $0.1 \mathrm{M}$ potassium phosphate buffer, and seven days later, the two upper leaves were challenge-inoculated with TMV $\left(10^{-5}\right)$; 2) the lower three leaves were neither inoculated nor rubbed with buffer, but the upper two leaves were inoculated with TMV seven days after decapitation; 3) the lower three leaves vere inoculated 
with TMV $\left(10^{-4}\right)$, but the upper two leaves vere neither inocu1ated nor rubbed with phosphate buffer; and 4) leaves were neithex inoculated nor rubbed with phosphate buffer after decapitation.

A11 experimental plants were kept in an air-conditioned greenhouse at approximate1y $23^{\circ} \mathrm{C}$. 
IDENTITY OF MICROBODIES IN HEALTHY AND VIRUS-INFECTED TOBACCO

Before investigating the possible correlation between cytoplasmic microbodies and the induction of acquired systemic resistance, it was necessary to have reliable methods of detecting and counting these organelles. Lower epidermal cells were selected because the microbodies in these cells could be viewed with the light microscope and the day-today variations in numbers of microbodies could be readily deterinined.

\section{Staining and Counting Microbodios}

Crystal-containing microbodies were detected in the cytoplasm of epidermal cells prepared by the method of Christie (2). Strips of tissue removed manually from the lower epidermis of tobacco were first submerged for 10-15 minutes in a $5 \%$ aqueous solution of octyphenoxypolyethoxyethano1 (Triton $\mathrm{X}-100$ ) to disrupt the chloroplast membranes so the chloroplasts would not interfere with viewing of the microbodies (Figure 1). After treatment with Triton $\mathrm{X}-100$, the epidermal strips were stained 10-15 minutes in a dye solution containing bromphenol blue in $2 \%$ gluteraldehyde and $0.2 \mathrm{M}$ citrate buffer at $\mathrm{pH} 3.5$.

Epidermal strips taken from upper leaves of decapitated tobacco plants were examined daily for 14 days following the 


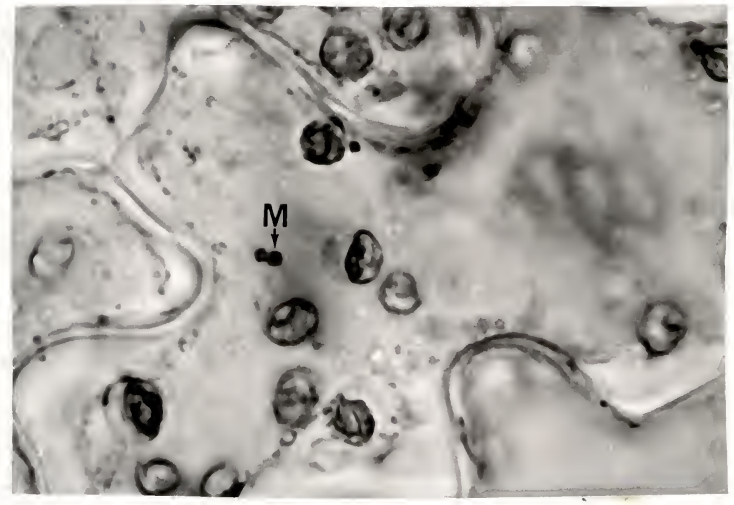

Figure 1. Crystallo1d inclusions of microbodies (ii) in epidermal cells that had not been treated with Triton $\mathrm{X}-100$ to remove chloroplasts. 
initial treatments. The numbers of microbodies in each of 20 cells per epidermal strip were counted.

It was evident from preliminary observations that the staining technique described above made possible the ready detection of microbodies in cells from healthy and TNVinfected plants (Figure 2). Reliability of the technique, however, depended upon whether numbers of microbodies per cell varied widely within a single leaf or within a single treatment. Results of preliminary experiments, in which microbodies were counted in cells of different epidormal strips from the same leaf, showed that only insignificant variations occurred within a leaf. For example, the average numbers of microbodies per cell in each of four strips from one healthy leaf were 19, 18, 18, and 17. Data from experiments described later in this dissertation, moreover, show that no significant variations in numbers of microbodies occurred within a single treatment.

Numbers of microbodies per cell did vary within a single epidermal strip, but this variation was positively correlated with cell size. Consequently, microbodies were counted only in cells of similar size.

Reliability of the previously described staining technique for quantitative measurements remained in doubt until it could be ascertained whether the early treatment of epidermal cells with Triton $\mathrm{X}-100$ had an effect on the numbers of detectable microbodies. It was possible that these cells 


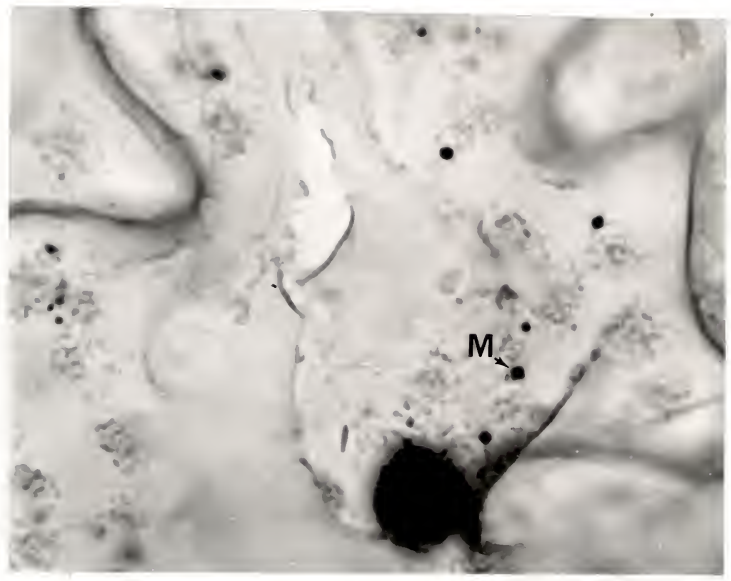

Figure 2. Cxystalloid inclusions of microbodies (M) in epidermal cells treated with Triton $X-100$ to remove chloroplasts. 
might contain microbodies which did not contain crystalloid inclusions and the chemical might destroy these microbodies or interfere with their staining as a consequence of its disruptive effect upon their membranes. Consequently, epidermal strips vere removed from the same healthy tobacco leaf, and half were treated with Triton $x-100$. Treated and nontreated strips of cells were stained and later examined for microbodies. That Triton $\mathrm{X}-100$ did not interfere with detection of microbodies was indicatod by the fact that about the same number of microbodies per cell were observed in treated and nontreated ones. In four epidermal sirips from the same 1eaf, counts in treated cells were 19 and 20 ; those in nontreated cel1s were 16 and 19.

Reliability of staining and counting techniques having been established it remained to test the observed microbodies for enzymatic activity in order to identify then with proviously described organelles (7).

\section{Catalase Activity in Microbodies of Epidermal Cells}

The crystal-containing organelles found in epidermal cells of 'Samsun NN' tobacco vere $0.5-2.0$ u in diameter and were identical in appearance to the microbodies described by Fredrick and Newcomb $(5,7)$. Since most or all catalase activity of the cell resides in microbodies (3), the crystalcontaining bodies in tobacco epidermal cells should be rich in catalase if they are indeed identical to microbodies. 
In two experiments, a total of six epidermal strips from tobacco were troatod so as to detect the site of catalase activity in the individual cells.

Lower epidermal strips were fixed in Karnovsky's solution (9), $\mathrm{pH} 7.2$, for $1-1.5$ hours. After fixation, the strips were rinsed for 15-20 minutes in three changes of $0.01 \mathrm{~N}$ neutral potassium phosphate buffer. The strips were then placed in a solution containing $10 \mathrm{mg}$ of $3,3^{\circ}-$ diaminobenzidine (DAB), $5 \mathrm{ml}$ of $0.05 \mathrm{M}$ propanediol buffer (2-amino-2-methy 1-1,3-propanedio1) at $\mathrm{pH} 10.0$, and $0.1 \mathrm{~m} 1$ of $3 \% \mathrm{H}_{2} \mathrm{O}_{2}$. The $\mathrm{pH}$ of the solution was adjusted to 9.0 prior to the addition of the epidermal strips. The strips were incubated in covered petri dishes for 30 minutes at $37^{\circ} \mathrm{C}$.

The epidermal strips were postfixed for 1 hour in $1 \%$ $\mathrm{OsO}_{4}$ in $0.01 \mathrm{H}$ neutral potassium phosphate buffer. They were then dehydrated in alcohol and mounted in Euparal for examination under the light microscope.

Crystal-containing bodies in epidermal cells of 'Samsun NN' tobacco always stained dark reddish-brown in DAB and $\mathrm{OsO}_{4}$ (Figuro 3), indicating strong catalase activity (7). The crystal-containing bodies did not stain in DAB and $\mathrm{OsO}_{4}$, provided epidermal strips had been pre-treated with 3-amino-1, 2,4-triazole, a known inhibitor of catalase activity (10). These results provide further evidence that the crystalcontaining bodies in epidermal cells of tobacco are the 


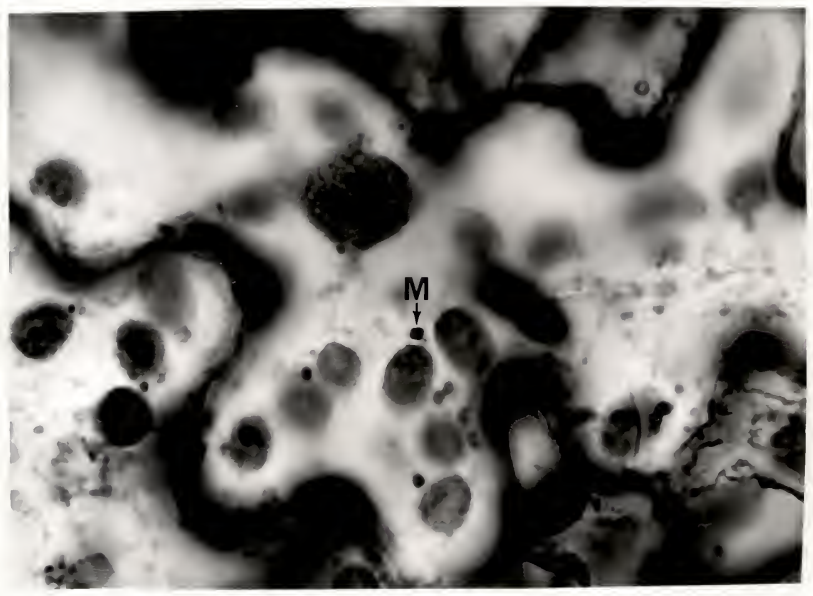

Figure 3. Crystalloid inclusions of microbodies (M) treated With diaminobenzidine and $\mathrm{OSO}_{4}$ for localization of catalase activity. 
same as the catalase-rich microbodies characterized by Froderick and Newcomb (7). 
THE INCREASE IN NUNBERS OF NICROBODIES IN RELATION

TO SYSTENIC INDUCED RESISTANCE OF TOBACCO TO THV

Now that the presence of microbodies in healthy plants has been demonstrated $(5,6,7,11)$, and since staining techniques described earlier make possible quantitative determinations of microbodies through light microscopy, it becomes possible to test the hypothesis of Israel and Ross (8) that microbodies may be correlated with the developmont of systemic induced resistance in hypersensitive hosts.

Microbodies were stained and counted as described earlier, and were countod daily for 14 days after the first inoculation or treatment in 20 cells per epidermal strip from the two upper leaves. The experinent was performed four times over a period of six months. A11 experimental plants were inoculated or inoculations were simulated as described in the section on methods of inoculation.

The numbers of microbodies in noninoculated control plants did not vary significantly over a 14 -day poriod after decapitation of the plants. An average of 14 to 19 microbodies per cell occurred in lower epidermal strips of these plants (Figure 4). Over the same 14-day period, moreover, on 1 y 14-18 microbodies were observed in resistant upper leaves that were not challenge-inoculated (Figure 5). In contrast, numbers of microbodies increased dramatically 


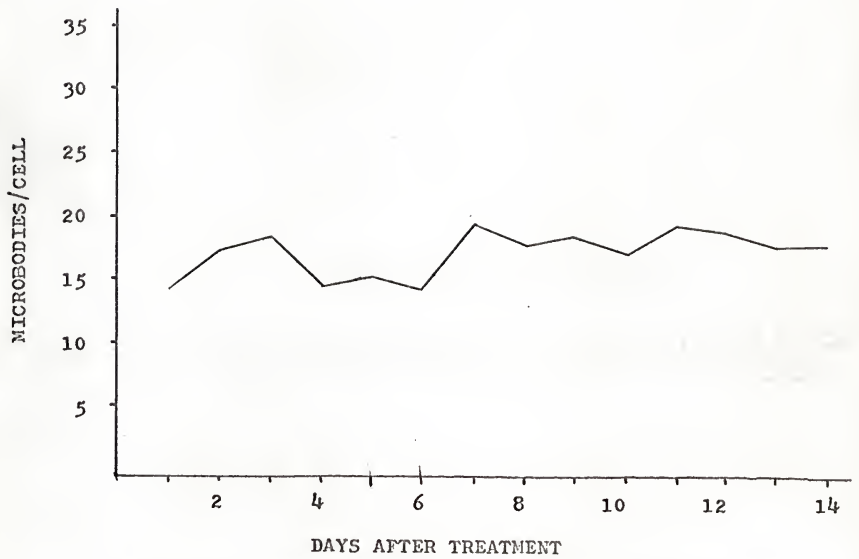

Figure 4. Average number of microbodies in 40 cells from two epidermal strips of leaves of control plants which were not inoculated. 


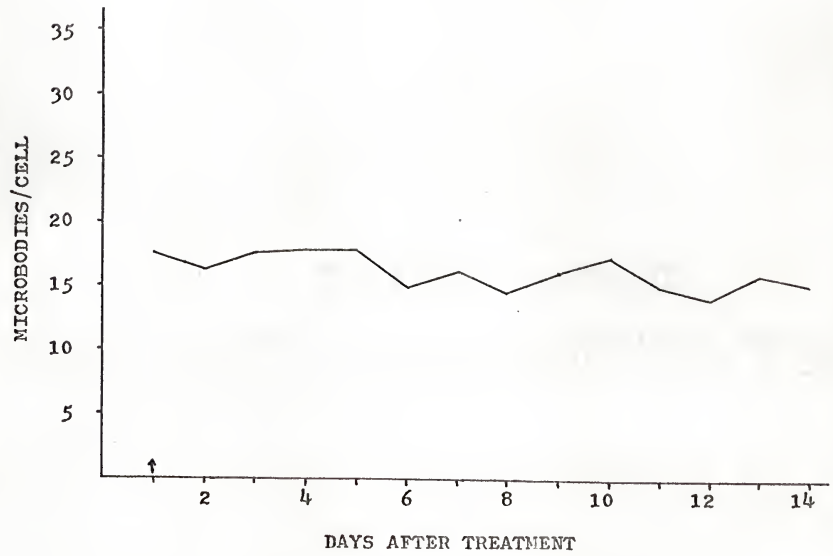

Figure 5. Average number of microbodies in $60 \mathrm{cells}$ from three epidermal strips of leaves of control plants which were only inoculated on the three lower leaves with TNV $\left(10^{-4}\right)$. Arrow indicates day of inoculation. 
in challenge-inoculated upper leaves in which resistance had been induced as a result of carlier inoculations of lower leaves. For example, 26 microbodies per cell were detected only one day after challenge-inoculation and 30 per cell were counted on the second day after the challengeinoculation (Figure 6). The numbers of microbodies por cell thus almost doubled in resistant leaves within 1-2 days of the socond, or challenge, inoculation. Numbers of microbodies also increased in epidermal cells of TMV-inoculated nonresistant leaves, but this increase did not occur until at least four days after inoculation of these leaves. Each cell contained 14-19 microbodies until the fourth day after inoculation, when the number increased about 1.6 fold to 29 (Figure 7 ). The same general trend was also found in plants where the lower three leaves were rubbed with $0.1 \mathrm{M}$ potassium phosphate buffor and the upper two leaves inoculated with TNV. Rubbing the lower leaves with buffer thus does not affect the number of microbodies in the upper leaves.

Results of these experiments suggest that microbodies increase in cells of hypersensitive tobacco prior to the reduction of lesion enlargement in both resistant and nonresistant leaves.

In resistant leaves the lesions increased very little in size, less than $0.2 \mathrm{~mm}$ per day, after the second day following the challenge-inoculation (Table 1). This is 


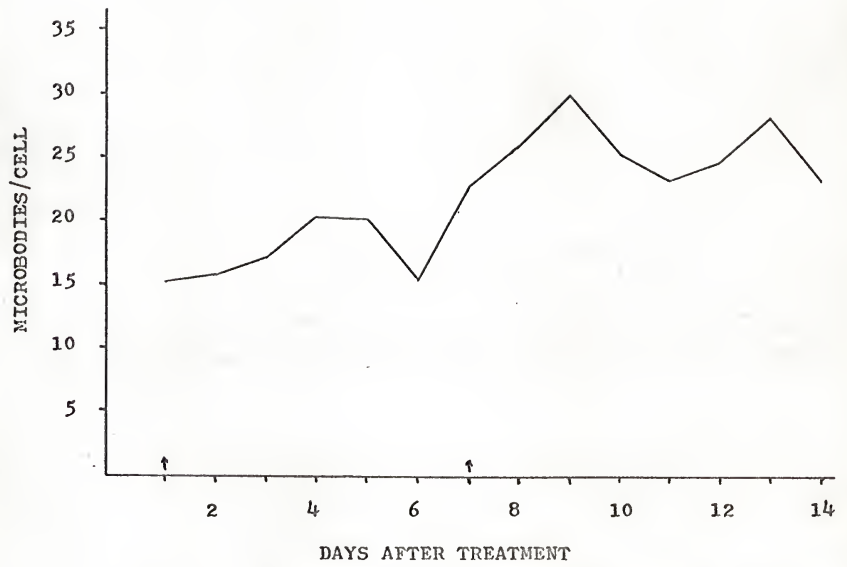

Figure 6. Average number of microbodies in $140 \mathrm{cells}$ from seven epidermal strips of leaves of plants which were inoculated on the three lower leaves with TNV $(10-4)$ and seven days later inoculated on the two upper leaves with TMV $\left(10^{-5}\right)$. Arrows indicate days of inoculation. 


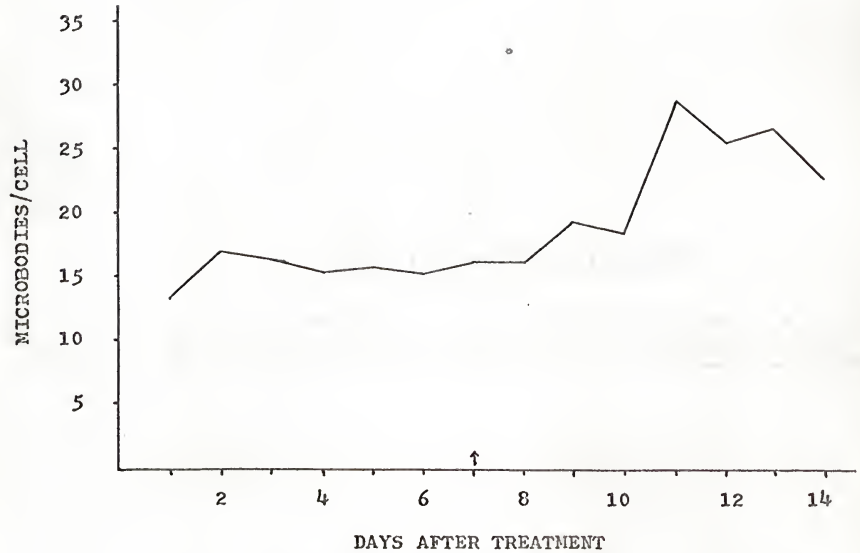

Figure 7. Average number of microbodies in 80 cells from four epidermal strips from leaves of plants which were only inoculated on the upper two leaves with TMV $\left(10^{-5}\right)$. Arrow indicates day of inoculation. 
Table 1. Daily increase in lesion size in upper leaves following inoculation with TNV $(10-5)$.a

Day

1

2

3

4

56

7

Resistant

Leaves
$0.7^{c}$
0.1
$0.2 \quad 0.1$
0.1
0.0

Nonresistant

Leavesd

$\begin{array}{lllllll}0.9 & 0.3 & 0.5 & 0.3 & 0.2 & 0.1\end{array}$
a Increase is expressed in $\mathrm{mm} / \mathrm{day}$.
b Lower leaves were inoculated with TMV $\left(10^{-4}\right)$ and upper leaves inoculated with THV $(10-5)$ soven days later.
c Average of at least 90 lesions.
d Only upper loaves wero inoculated with TNV (10-5). 
in contrast to the nonresistant leaves where the lesions continued to increase more than $0.2 \mathrm{~mm}$ per day in size for five days following inoculation.

If there is any association between the increase of the microbodies and the mechanism that limits lesion size, then the microbodies should increase in number prior to the reduction in lesion growth. As was pointed out earlier, the numbers of microbodies in the resistant leaves began to increase one day following the challenge-inoculation, and there vas a substantial reduction in lesion growth on the third day. In nonresistant leaves, the microbodies did not begin to increase in number until four days following the inoculation, and there was not a substantial reduction in lesion growth until the sixth day. In both resisiant and nonresistant leaves, numbers of microbodies began to increase two days prior to any substantial reduction in lesion growth. In resistant leaves, however, the increase in numbers of microbodies and the reduction in lesion Erowth occurred three days earlier than in nonresistant 1eaves.

This correlation of numbers of microbodies with growth of lesions sugeests that microbodies are somehow involved in or stimulated by the normal mechanisms that 1 imit lesion development in hypersensitive hosts. The fact that numbers of microbodies increase almost immediately after challengeinoculation of resistant leaves is consistent with Ross's 
hypothesis that induced resistance results from enhancoment of the normal resistant mechanisms of hypersensitive hosts (15). 


\section{DISCUSSTON}

Pathogens that cause a localized necrosis in plants induce a systemic resistance to subsequent infection by viruses that cause local lesions $(1,13,14,15)$. It has been suggested that the nature of the induced resistance is the result of the enhancement of the plant defense reactions which normally limit lesion size (15).

Israel and Ross (8) suggested that crystal-containing bodies in a zone of palisade parenchyma cells surrounding TMV-lesions in challenge-inoculated leaves may be involved in defonse reactions. Simons and Ross (18) 1ater demonstrated a greater and earlier increase in peroxidase activity in upper leaves of challenge plants than of control plants. They suggested that the early increase of peroxidase activity in challenge leaves may play some role in the enhancement of the normal plant defense reactions. Except for these reports, no other substantial suggestions have been made that could account for the differences in lesion size in challenge and control leaves.

Simons and Ross (18) also reported that catalase activity increased prior to lesion formation in the challenge leaves. Since most or all of the catalase activity is 10calized in the microbodies (3), the increase in catalase activity is most logically explained by the increase in 
the number of microbodies prior to lesion formation in the - cha1lenge leaves.

The increase in numbers of microbodies in the challenged leaves begins before lesion formation and reaches a peak about the time of Iesion formation. In control plants, the microbodies do not significantly increase in numbers in the upper leaves until the fourth day after inoculation. Lesions in control leaves continue to increase in size for five days after their appearance; but in challenge leaves there is no substantial increase in lesion size following the day they appear. The numbers of microbodies increased three days earlier in challenge leaves than in control 1eaves. In both instances, however, the microbodies increase before any substantial decrease in the rate of lesion growth. The fact that lesions increase in size vexy littlo following the increase in numbers of microbodies sugests that the build-up of the microbodies may be associated with the enhancement of the normal defense reactions. At this point it is not possible to determine a specific function of the microbodies in systemic acquired resistance. It has been shown that peroxisomes (microbodies) contain, in addition to catalase, the enzyme systems involved with glycolate metabolism (12), which is a byproduct of photosynthesis. It has also been pointed out by de Duve (4) that the respiratory system of peroxisomes (microbodies) is not coupled to any mechanism for the conservation of energy, 
and it catalyses an essentially wasteful form of respiration. This may be significant if there is in fact a rapid increase of microbodies in virus-infected cells inmediately prior to lesion formation in cells surrounding a lesion.

Ross and Israel (16) have suggested that cells surrounding a lesion are sensitive to collapse and the increased sensitivity of these cells to collapse may be instrumental in viral localization in plants. It is not known if tho Increase of microbodies plays a role in making a cell more sensitive to collapse following viral replication in that ce11, but it is interesting that the respiratory system of microbodies is not linked to the energy-conserving steps found in some metabolic pathways. Israel and Ross (8) also pointed out that cells in a zone surrounding a lesion resemble cells that are in an active metabolic state, which is energy-requiring. If there is an increase of microbodies, whose enzyme systoms are breaking down products without the usual energy return, then cells surrounding the lesion may reach a state that would make them more sensitive to collapse. Although Simons and Ross (18) reported an increase in catalase activity in challenge leaves, they did not find a corresponding increase in glycolic acid oxidase. This result is somewhat puzzling since glycolic acid oxidase is also associated with microbodies $(12,19,20)$. Tolbert et al. (19) reported that glycolate oxidase activity was increased by $30-40 \%$ when the peroxisomal (microbody) fraction was treatod 
with Triton $\mathrm{x}-100$. It may be that increases in glycolate oxidase activity cannot be accurately determined unless the microbody membranes are solubilized.

The role of microbodies in systemic induced rosistance is certainly not yot understood. But results reported herein clearly associate microbodies in whatever derensive mechanism hypersensitive tobacco has to limit the enlargement of lesions caused by TMV. 
SUMARY

Crystal-containing bodies in lower epidermal cells of "Samsun NN" tobacco are identical to "microbodies" ("peroxisomes, cytosomes, crystal-containing bodies"). Identity was based on the positive staining reaction for catalase activity with diaminobenzidine and the similarities in the size of the crystal-containing bodies and microbodies.

Treatment of epidermal ce11s with Triton $\mathrm{X}-100$ to disrupt the chloroplasts did not affect the number of microbodies per cell.

There was a three-day lag between the time microbodies began to increase in challenge plants and control plants. In challonge plants, inoculated with tobacco mosaic virus (TMV) first on the lower three leaves and seven days 1ater inoculated on the upper two leaves, there vas a $1.5-$ fold increase in the microbodies only one day following challenge inoculation and a 1.9-fold increase on the second day. In control plants, inoculated with TMV only on the upper two leaves, the microbodies did not begin to increase until four days after inoculation.

There was a.substantial decrease in the rate of lesion Erowth in challenge leaves two days after the second, or 
challenge, inoculation. In control leaves, there was no substantial decrease in rate of lesion growth until the sixth day after inoculation. In both challengo and control leaves, there was an increase in the number of microbodies prior to the time of a substantial decrease in lesion growth. It is thought that: 1) the increase or microbodies may play a role in the restrictions of lesion growth, in challenge and control leaves; and 2) that the earlier increase of microbodies in challenge leaves may have some role in the earlier reduction or rate of lesion enlargement in these leaves than in control leaves. 


\section{LITERATURE CITE])}

1. Bozarth, R. F., and A. F. Ross. 1.964. Systemic resistance by localized virus infections: Extent of changes in uninfected plant parts. Virology 24: $446-455$.

2. Christie, R. G. 1971. (Personal Communication).

3. de Duve, C., and P. Baudhuin. 1966. Peroxisones (microbodies and related particles). PhysioloGical Reviews 46: 323-357.

4. de Duve, C. 1969. The peroxisome: a new cytoplasnic organelle. Proc. Roy. Soc. (Lond.) 173: $71-83$.

5. Frederick, S. E., E. H. Newcomb, E. L. Vigil, and W. P. Wergin. 1968. Fine structural characterizations of plant microbodies. Planta 81: 229-252.

6. Frederick, S. E., and E. H. Newcomb. 1968. Microbody-1ike organolles in leaf cel1s. Science 163: $1353-1355$.

7. Frederick, S. E., and E. H. Newcomb. 1969. Cytochemical localization of catalase in leaf microbodies (peroxisomes). J. Coll Biol. 43: 343-353.

8. Israel, II. Wo, and A. F. Ross. 1967. The fine structure of local lesions induced by tobacco mosaic virus in tobacco. Virology 33: $272-286$.

9. Karnovsky, M. J. 1965. A formaldehyde-glutaraldehyde fixativo of high osmolality for use in electron microscopy. J. Cell Biol. 27: 137A-138A.

10. Nargoliash, E., and A. Novogrodsky. 1958. A study of the inhibition of catalase by 3-amino-1:2:4triazole. Biochem. J. 68:468-475.

11. Mollenhauer, H. H., D. J. Moore, and A. G. Kelley. 1966. The widespread occurrence of plant cytosomes resembling animal microbodies. Protoplasma 62: $44-52$.

12. Kisaki, T., and N. E. Tolbert. 1969. Glycolate and glyoxylate metabolism by isolated peroxisomes or ch1oroplasts. Plant Physiol. 44: 242-250. 
13. Ross, A. F., and R. F. Bozarth. 1960. Resistance induced in one plant part as a result of virus infection in another part. Phytopathology 50: 652. (Abstract).

14. Ross, A. F. 1961. Systemic acquired resistance induced by localized virus infections in plants. virology 14: $340-358$.

15. Ross, A. F. 1966. Systemic effects of 10 al lesion formation, p. 127-150. In A. B. R. Beemster and Jeanne Dijkstra (ed.). Viruses of Plants. NorthHo11and Publ. Co., Amsterdam.

16. Ross, A. F., and II. W. Israe1. 1970. Use of hoat treatments in the study of acquired resistance to tobacco mosaic virus in hypersensitive tobacco. Phytopathology 60: 755-770.

17. Simons, $T$. J., and A. F. Ross. 1970. Enhanced peroxidaso activity associated with induction of resistance to tobacco mosaic virus in hypersensitive tobacco. Phytopathology 60: 383384.

18. Simons, T. J., and A. F. Ross. 1971. Metabolic changes associatod with systemic induced resistance to tobacco mosaic virus in Samsun NN tobacco. Phytopathology 61: 293-300.

19. Tolbert, N. E., A. Oeser, R. K. Yamazaki, R. H. Hageman, and $\uparrow$. Kisaki. 1969. A survey of plants for leaf peroxisomes. Plant Physio1. 44: 135-147.

20. Tolbert, N. E., A. Oeser, T. Kisaki, R. H. Hageman, and R. K. Yamazaki. 1968. Peroxisomes from spinach leaves containing enzymes related to glycolate metabolism. J. Biol. Chem. 243: 51795184.

21. Zimmer, D. E. 1970. Fine structure of Puccinia carthami and the u1trastructural nature of exclusionary seediine-rust resistance of safflower. Phytopathology 60: 1157-1163. 


\section{BIOGRAPHICAL SKETCH}

Marvin Edward Miller was born February 27, 1941, at Dawson, Georgia. He attended Erammar school at Dawson and eraquated in 1959 from North Narion High School at Roddick, Florida. He attonded Abraham Balduin Junior College at Tifton, Georgia for one year. From 1960 unt3.1 1964 he served as an electronics technician in the United States Navy and was stationed at Pensacola, Florida. Following his release from the Navy he entered the University of Florida, where he received the dogree of Bachelor of Science in Agriculture in August, 1967 and the degree of Master of Science in March, 1969. In Apr11, 1969, he began studies toward the degreo of Doctor of Philosophy. He is a member of the American Phytopathological Society, Alpha Zeta, and Gamma Sigma Delta.

Marvin Edward Miljer is married to the former Maxine Childress of Fairhope, Alabama. 
I certify that I have read this study and that in my opinion it conforms to acceptable standards of scholarly presentation and is fully adequate, in scope and quality, as a dissertation for the degree of Doctor of Philosophy.

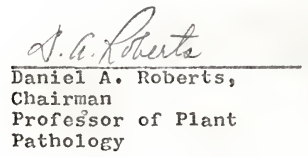

I certify that $I$ have read this study and that in my opinion it conforms to accoptable standards of scholarly presentation and is fully adequate, in scope and qualify, as a dissertation for the degree of Doctor of Philosorfay.

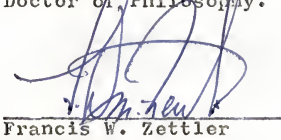

Assistant Professor of Plant Pathology

$I$ certify that $I$ have read this study and that in my opinion it conforms to acceptable standards of scholarly presentation and is fully adequate, in scopo and quality, as a dissertation for the degree of Doctor of Philosophy.

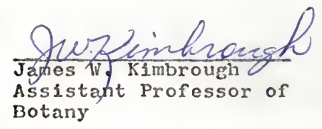


I certify that $I$ have read this study and that in my opinion it conforms to acceptable standards of scholarly presentation and is fully adequate, in scope and quality, as a dissertation for the degree of Doctor of Philosophy.

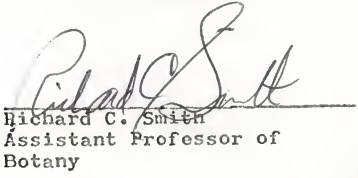

This dissertation was submitted to the Dean of the College of Agriculture and to the Graduate Council, and was accepted as partial fulfillment of the requirements for the degree of Doctor of Philosophy.

June, 1971

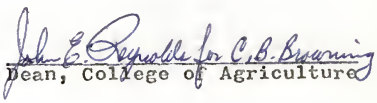

Dean, Graduate School 